кандидат юридических наук, доцент кафедры гражданского процесса Кубанского государственного аграрного университета имени И.Т. Трубилина

\section{ПРОЦЕССУАЛЬНОЕ ПРАВОПРЕЕМСТВО ОРГАНОВ МЕСТНОГО САМОУПРАВЛЕНИЯ: ОТ ВЫСШЕГО ДОЛЖНОСТНОГО ЛИЦА К МЕСТНОЙ АДМИНИСТРАЦИИ}

\begin{abstract}
Аннотация:
Статья представляет собой небольшое аналитическое исследование, произведенное на основании материалов реального арбитражного дела, изучение которого побудило к поиску ответов на вопросы, возникшие в ходе ознакомления с ним. Предметом исследования явился случай процессуального правопреемства от высшего должностного лица муниципального образования к местной администращии при разрешении заявления хозяйственного общества о взыскании судебных расходов по делу, в результате разрешения которого глава муниципального образования был определен судом как субъект публичной юридической ответственности с возложением на него определенной публично-правовой обязанности, тогда как моменту процессуального правопреемства предшествовало досрочное прекращение полномочий должностного лица в связи с его отставкой по собственному желанию. В статье исследуются такие юридические факты и состояния, как досрочное прекращение публичных полномочий должностного лица и осуществление его функций иными лицами для обеспечения участия в coomветствующих правоотношениях, гражданско-правовое или функциональное правопреемство как необходимое условие осуществления процессуального правопреемства, юридическая ответственность и сопутствующие меры, а также их общая взаимосвязь и взаимозависимость.
\end{abstract}

Ключевые слова:

глава муниципального образования, муниципальное образование, орган местного самоуправления, процессуальное правопреемство, гражданско-правовое правопреемство, функциональное правопреемство, публичная юридическая ответственность, досрочное прекращение полномочий, индивидуализация и неотвратимость ответственности.
PhD in Law, Associate Professor, Civil Process Department Kuban State Agrarian University

\section{PROCEDURAL SUCCESSION OF LOCAL GOVERNMENT \\ AUTHORITIES: FROM THE HIGHEST OFFICIAL TO THE LOCAL ADMINISTRATION}

Summary:

The paper is a brief analytical study based on real arbitration case leading to the search for answers during its review. The research focuses on the case of procedural succession from the highest official of the municipality to local administration while dealing with business entity statement on the collection of court fees resulted in the determination of the head of the municipality as an actor of public legal liability to be charged with public law duties, whereas the procedural succession is preceded by the early termination of official's powers due to the resignation at his own request. The research examines such legal facts and status as an early termination of an official's public powers and the discharge of his responsibilities by other persons provided for his participation in legal relations, civil legal succession or succession of responsibilities as a prerequisite for procedural succession, legal liability and collateral measures as well as their correlation and interdependence.

Keywords:

head of the municipality, municipality, local government authority, procedural succession, civil legal succession, succession of responsibilities, public legal liability, early termination of powers, individualization and inevitability of liability.

Решением арбитражного суда признано незаконным бездействие главы муниципального образования, выразившееся в нерассмотрении обращения хозяйственного общества и ненаправлении копии ответа. Суд обязал главу муниципального образования в месячный срок со дня вступления решения в законную силу устранить допущенные нарушения прав и законных интересов хозяйственного общества путем направления письменного ответа.

После вступления решения в законную силу хозяйственное общество обратилось в арбитражный суд с заявлением о взыскании с администрации муниципального образования судебных расходов, тогда как администрация муниципального образования не являлась лицом, участвующим в описываемом арбитражном деле. При производстве по заявлению о взыскании судебных расходов определением арбитражного суда в порядке процессуального правопреемства произведена замена стороны главы муниципального образования на администрацию муниципального образования. При этом следует отметить, что предварительно отдельным определением, выне- 
сенным в ходе рассмотрения заявления хозяйственного общества о взыскании судебных расходов, арбитражный суд известил администрацию муниципального образования о содержании рассматриваемых требований, а также о том, что они направлены именно к ней.

Процессуальным следствием описанной ситуации явилось вынесение арбитражным судом определения о взыскании с администрации муниципального образования в пользу хозяйственного общества судебных расходов на оплату услуг представителя. Законность данного судебного акта была проверена апелляционной и кассационной инстанциями.

Как следует из содержания судебных актов, поводом для процессуального правопреемства и произведенного взыскания явилось досрочное прекращение полномочий главы муниципального образования и принятие его отставки представительным органом местного самоуправления, т. е. выбытие, по мнению судов, лица в правоотношении.

Статья не содержит и не предполагает критических замечаний в отношении вступивших в законную силу судебных актов, равно как и сомнений в правильности применения норм материального и процессуального права судами, использованных ими правоприменительных подходов. Не имеет она и цели каким-то иным образом противопоставить мнение автора фрактическому результату разрешения заявления о взыскании судебных расходов по конкретному арбитражному делу.

Описанные процессуальные обстоятельства использованы в большей степени в качестве исходных условий для моделирования фабулы статьи. Содержание же статьи обусловлено двумя процессуально-практическими вопросами, возникшими в ходе изучения материалов арбитражного дела, а именно:

- о допустимости такого процессуального правопреемства, учитывая то, что в силу ч. 1 ст. 48 Арбитражного процессуального кодекса Российской Федерации (далее - АПК РФ) [1] для наступления процессуального правопреемства в рамках арбитражного дела необходимо, чтобы в реальной действительности наступило правопреемство в материальном правоотношении;

- о юридической согласованности допущенного процессуального правопреемства с установленной ранее этим же составом суда юридической ответственностью для лица, допустившего неправомерное поведение в форме бездействия, с учетом принципов индивидуализации и неотвратимости такой ответственности.

В соответствии с ч. 1 ст. 48 АПК РФ, в случаях выбытия одной из сторон в спорном или установленном судебным актом арбитражного суда правоотношении (реорганизация юридического лица, уступка требования, перевод долга, смерть гражданина и другие случаи перемены лиц в обязательствах) арбитражный суд производит замену этой стороны ее правопреемником и указывает на это в судебном акте [2].

Полагаем, что наиболее актуальные ответы на обозначенные вопросы возможно получить, используя критичный подход к описанному и рассматриваемому в данной аналитической статье процессуальному правопреемству, а для обеспечения такого подхода предлагаем избрать роль заинтересованного лица по делу, т. е. администрации муниципального образования, как субъекта, не согласного с вынесенным определением, и рассмотреть ее доводы на предмет их обоснованности, но в то же время принимая во внимание правоприменительные подходы, использованные судебными инстанциями.

Первый из доводов заключается в том, что произведенная судом первой инстанции замена заинтересованного лица допущена вне контекста ч. 1 ст. 48 АПК РФ, поскольку процессуальное правопреемство возможно только при условии, если состоялось правопреемство в материальноправовом смысле [3].

Классифицируя случаи правопреемства в материальном правоотношении, их можно разделить на следующие группы:

- обусловленные гражданско-правовым правопреемством,

- обусловленные функциональным правопреемством.

В силу положений ст. 125 Гражданского кодекса Российской Федерации, ст. 36,37 Федерального закона от 6 октября 2003 г. № 131-Ф3 «Об общих принципах организации местного самоуправления в Российской Федерации» [4], во-первых, глава муниципального образования и администрация муниципального образования (местная администрация), являясь самостоятельными органами местного самоуправления, тем не менее представляют в гражданских правоотношениях одного и того же субъекта - муниципальное образование, т. е. действуют от имени и в интересах одного лица перед третьими лицами; во-вторых, глава муниципального образования руководит местной администрацией на принципах единоначалия. Таким образом, с учетом существующих общеобязательных правил поведения, содержащихся в указанных нормах, ни глава муниципального образования, ни местная администрация не могут быть субъектами гражданско-правового правопреемства, в объеме которого один из них мог бы стать правопреемником другого. 
Следует также отметить, что досрочное прекращение полномочий главы муниципального образования в связи с отставкой по собственному желанию лица, замещавшего данную должность, не является юридическим фрактом, с которым действующие источники права связывают наступление случая перемены лица в обязательстве, поскольку данный юридический факт, вопервых, не влечет прекращение существования самой должности (органа местного самоуправления), а во-вторых, в гражданских правоотношениях физическое лицо, действующее как глава муниципального образования, не является и не может являться самостоятельным субъектом гражданских правоотношений в данном качестве, поскольку через него опосредуется участие муниципального образования в этих правоотношениях.

Не менее интересным для анализа является и рассмотрение вопроса о допустимости процессуального правопреемства от одного органа местного самоуправления к другому в случае функционального правопреемства.

Согласно ч. 1 ст. 48 АПК РФ, правопреемство возможно в силу прямого указания закона и может не основываться на гражданско-правовом правопреемстве [5].

Наступление случая функционального правопреемства описано в п. 17 Указа Президента Российской Федерации от 12 мая 2008 г. № 724 «Вопросы системы и структуры федеральных органов исполнительной власти», и оно характеризуется как обусловленное передачей функций одних преобразуемых или упраздняемых публичных органов иным публичным органам, что влечет правопреемство по обязательствам, в том числе по обязательствам, возникшим в результате исполнения судебных решений [6].

Досрочное прекращение полномочий лица, замещавшего должность главы муниципального образования, в связи с его отставкой по собственному желанию характеризуется следующими юридически значимыми обстоятельствами:

- прекращением публичных полномочий и специального правового статуса физического лица,

- прекращением трудовых правоотношений физического лица (работника) с работодателем.

В то же время сам публичный орган, а именно орган местного самоуправления - глава муниципального образования, не прекращает своего существования и не претерпевает какихлибо юридических трансформаций.

Т. е. досрочное прекращение полномочий лица, замещавшего должность главы муниципального образования, в связи с его отставкой по собственному желанию не только не характеризуется преобразованием или упразднением самой должности высшего должностного лица муниципального образования, которое в качестве самостоятельного субъекта публичных правоотношений составляет структуру органов местного самоуправления муниципального образования и наделяется собственными полномочиями по решению вопросов местного значения, но и не сопровождается передачей его функций, в частности, исполнительно-распорядительному органу муниципального образования (местной администрации).

Разрешая заявление о взыскании судебных расходов, судебные инстанции, обозначая в судебных актах правоприменительный подход по делу, привели содержание абз. 2 п. 1 постановления Пленума Высшего арбитражного суда Российской Федерации от 22 июня 2006 г. № 23 «О некоторых вопросах применения арбитражными судами норм Бюджетного кодекса Российской Федерации», т. е. указали на то, что суду, разрешающему требования, направленные к публично-правовому образованию, надлежит выяснить, какой орган на основании п. 10 ст. 158 Бюджетного кодекса Российской Федерации как главный распорядитель бюджетных средств должен выступить в суде от имени публично-правового образования [7].

Вместе с тем для сделанных выше в статье выводов проверочную практическую ценность имеет правоприменительная позиция, изложенная в абз. 3 п. 1 указанного постановления Пленума Высшего арбитражного суда Российской Федерации, согласно которой в том случае, если государственный (муниципальный) орган, являвшийся главным распорядителем бюджетных средств на момент возникновения спорных правоотношений, утратил соответствующий статус (в связи с передачей соответствующих полномочий иному органу или в связи с ликвидацией), в качестве представителя публично-правового образования надлежит привлекать орган, обладающий необходимыми полномочиями на момент рассмотрения дела в суде, а при отсутствии такового (в случае если соответствующие полномочия не переданы иному органу) - соответствующий финансовый орган публично-правового образования [8].

Данные правоприменительные рекомендации еще раз обращают наше внимание на то, что независимо от отраслевого характера правоотношений в том случае, если суд сталкивается с необходимостью процессуальной замены представителя публично-правового образования, принципиальное значение для определения и формирования надлежащего субъектного состава лиц, участвующих в деле, имеет, равно как и является юридически необходимым, установление 
органа, осуществляющего полномочия органа, утратившего соответствующий статус. Однако досрочное прекращение полномочий лица, замещавшего должность главы муниципального образования, в связи с его отставкой по собственному желанию не влечет утрату статуса таким органом местного самоуправления, как глава муниципального образования. Более того, местная администрация в подобных случаях не осуществляет и не может осуществлять полномочия главы муниципального образования не только по причине того, что, как указано в ст. 36, 37 Федерального закона от 6 октября 2003 г. № 131-Ф3 «Об общих принципах организации местного самоуправления в Российской Федерации», они обладают самостоятельными полномочиями [9], а в большей степени потому, что при прекращении осуществления фризическим лицом полномочий высшего должностного лица муниципального образования в силу описываемых причин соответствующие полномочия реализуются, как правило, его первым заместителем, т. е. происходит замещение физического лица, а не органа.

Проведенный анализ в аспекте норм публичного, административного и гражданского права не позволил обнаружить наличие правовых оснований наступления процессуального правопреемства в арбитражном процессе в случае, когда фризическое лицо добровольно и в установленном законом порядке прекратило участие в публичных и гражданских правоотношениях в связи с прекращением осуществления этим лицом трудовой функции.

Отдельного внимания требует вопрос, обозначенный в статье как побудительный мотив, наряду с уже рассмотренным, о дозволительности процессуального правопреемства, учитывая ранее установленную для правопредшественника меру ответственности в виде определенной обязанности.

Необходимо отметить, что спорное правоотношение, разрешенное вступившим в законную силу решением арбитражного суда, связано с осуществлением права на обращение в государственные органы и органы местного самоуправления, порядок реализации которого закреплен Федеральным законом от 2 мая 2006 г. № 59-Ф3 «О порядке рассмотрения обращений граждан Российской Федерации» [10]. Фактически спорное правоотношение возникло по поводу рассмотрения письменного обращения хозяйственного общества, адресованного исключительно и конкретно главе муниципального образования, которое не было рассмотрено в установленный законом срок. Следуя бланкетному содержанию нормы права, закрепленной в ст. 15 указанного федерального закона, лица, виновные в нарушении данного фредерального закона, несут ответственность, предусмотренную Кодексом Российской Федерации об административных правонарушениях (далее - КоАП РФ) [11].

В свою очередь в положениях ст. 5.59 КоАП РФ однозначно и безусловно закреплено, что нарушение установленного законодательством Российской Федерации порядка рассмотрения обращений граждан, объединений граждан, в том числе юридических лиц, в частности, должностными лицами органов местного самоуправления влечет наложение административного штрафа на правонарушителя [12]. При этом общие правила привлечения к административной ответственности не допускают возможности освобождения от нее в связи с утратой специального статуса, в тех случаях когда правонарушение было совершено в период наличия такого статуса у лица.

Спорное правоотношение, связанное с рассмотрением обращения общества, является по своему характеру материальным публичным и предполагает установление юридической ответственности для лица, совершившего административное правонарушение, в силу приведенной нормы КоАП РФ, с учетом принципа ее индивидуализации. Т. е. если субъектом спорного правоотношения и правонарушителем является должностное лицо, то ответственность фрактически будет установлена для физического лица, обладающего специальным правовым статусом, а именно статусом должностного лица, но никак не для иных лиц, в том числе органов, которые правонарушитель возглавляет (возглавлял) как руководитель.

Отдельного акцента требует обязанность, к исполнению которой суд принудил должностное лицо. Эта обязанность обусловлена не состоянием «кредитор - должник», т. е. не состоянием обязательства, в котором установление (определение) объема обязанности предполагает и допускает наличие свободной и доброй воли лиц, имеющих желание (намерение) стать участниками правоотношения, а в последующем позволяет уже сторонам обязательства изменять порядок и способы исполнения возникшей обязанности, а также прекращать ее, в частности путем прощения. Обязанность, в силу которой должностному лицу надлежит в месячный срок со дня вступления в законную силу решения устранить допущенные нарушения прав и законных интересов хозяйственного общества, обусловлена фрактом правонарушения в области публичных правоотношений и по сути своей является мерой юридической ответственности, установленной государством и обеспеченной государственным принуждением, и в качестве обязанности фактически представляет собой меру воздействия на правонарушителя, содержащую неблагоприятные последствия конкретно и исключительно для него, избежать которые не представляется возможным в силу действующих обще- 
обязательных правил поведения и характера правонарушения, за которое установлена ответственность. При этом установление обязанности и наступление неблагоприятных последствий происходят помимо воли лица (правонарушителя), т. е. не зависят от нее.

Обязанность, возложенная решением арбитражного суда на конкретного субъекта первоначальных спорных публичных правоотношений, в первую очередь свидетельствует об удостоверении судом фракта совершения этим лицом проступка и применении к нему меры ответственности, т. е. утрата субъектом ответственности специального статуса не изменяет и не может изменить юридическую оценку его поведения, а следовательно, не может являться основанием для освобождения от такой сопутствующей меры, как судебные расходы.

Учитывая изначальную оговорку в настоящей статье относительно факта вступления в законную силу судебных актов по конкретному арбитражному делу и их непререкаемости, изложенное все же позволяет сделать следующие исследовательские констатации.

- Лица, участвующие в деле, не являлись участниками гражданских правоотношений, в частности и таких, которые бы характеризовались состоянием обязательства, а сами спорные правоотношения являлись публичными и не сопровождались функциональным преобразованием субъекта, обладающего властно-распорядительными полномочиями, с передачей его фрункций иным лицам, т. е. правопреемство в материальном правоотношении не произошло.

- Возложенная решением арбитражного суда обязанность является мерой публичной юридической ответственности, установление которой для правонарушителя предполагает неотвратимость и индивидуализацию, т. е. не допускается исполнение обязанности третьим лицом, как это, к примеру, допустимо при наступлении деликтной ответственности.

- Наличие факта наступления публичной ответственности путем принуждения к исполнению публичной обязанности, пусть даже и в отсутствие фракта привлечения к административной ответственности, надлежит учитывать как юридически значимое обстоятельство при разрешении вопроса о процессуальном правопреемстве, в частности в подобных описанному делах.

- Сама по себе утрата субъектом процессуальных правоотношений специального статуса, в частности такого, как высшее должностное лицо муниципального образования, недостатки его поведения в которых породили его же принуждение к исполнению публичной обязанности, не может и не должна позволять такому лицу избегать наступления сопутствующих мер, в том числе таких, как взыскание судебных расходов, путем допущения процессуального правопреемства.

\section{Ссылки:}

1. Арбитражный процессуальный кодекс Российской Федерации [Электронный ресурс] : федер. закон Рос. Федерации от 24 июля 2002 г. № 95-Ф3 : ред. от 28 дек. 2017 г. Доступ из справ.-правовой системы «КонсультантПлюс».

2. Там же.

3. Определение Судебной коллегии по экономическим спорам Верховного суда Российской Федерации от 22 апр. 2015 г. № 302-ЭС15-493 по делу № А58-2339/1998 [Электронный ресурс]. Доступ из справ.-правовой системы «Гарант».

4. Гражданский кодекс Российской Федерации (часть первая) [Электронный ресурс] : федер. закон Рос. Федерации от 30 нояб. 1994 г. № 51-Ф3 : ред. от 29 дек. 2017 г. Доступ из справ.-правовой системы «КонсультантПлюс» ; Об общих принципах организации местного самоуправления в Российской Федерации [Электронный ресурс] : федер. закон Рос. Федерации от 6 окт. 2003 г. № 131-Ф3 : ред. от 29 дек. 2017 г. Доступ из справ.-правовой системы «КонсультантПлюс».

5. Определение Верховного суда Российской Федерации от 22 нояб. 2014 г. № 308-КГ14-1033 [Электронный ресурс]. Доступ из справ.-правовой системы «Гарант».

6. Вопросы системы и структуры федеральных органов исполнительной власти [Электронный ресурс] : указ Президента РФ от 12 мая 2008 г. № 724 : ред. от 23 нояб. 2016 г. Доступ из справ.-правовой системы «КонсультантПлюс».

7. О некоторых вопросах применения арбитражными судами норм Бюджетного кодекса Российской Федерации [Электронный ресурс] : постановление Пленума Высшего арбитражного суда РФ от 22 июня 2006 г. № 23 . Доступ из справ.правовой системы «КонсультантПлюс».

8. Там же.

9. Об общих принципах ...

10. О порядке рассмотрения обращений граждан Российской Федерации [Электронный ресурс] : федер. закон от 2 мая 2006 г. № 59-Ф3 : ред. от 27 нояб. 2017 г. Доступ из справ.-правовой системы «КонсультантПлюс».

11. Там же.

12. Кодекс Российской Федерации об административных правонарушениях [Электронный ресурс] : федер. закон Рос. Федерации от 30 дек. 2001 г. № 195-Ф3 : ред. от 31 дек. 2017 г. Доступ из справ.-правовой системы «КонсультантПлюс». 